\title{
CURRÍCULO POR COMPETÊNCIAS NA ÁREA DE BIODIAGNÓSTICO: DESAFIOS DE IMPLANTAÇÃO
}

\author{
SKILL-BASED CURRICULUM IN BIOLOGICAL DIAGNOSIS: \\ IMPLEMENTATION CHALLENGES
}

\author{
Maria Beatriz S. C. de Oliveira ${ }^{1}$ \\ Wânia Regina Coutinho Gonzalez²
}

Resumo O presente trabalho objetivou investigar a adoção da noção de competências na organização curricular do Curso Técnico de Laboratório em Biodiagnóstico em Saúde, da Escola Politécnica de Saúde Joaquim Venâncio (EPSJV), unidade técnico-científica da Fundação Oswaldo Cruz (Fiocruz). A pesquisa enfocou a viabilidade da ressignificação desse modelo a partir da adoção da matriz crítico-emancipatória proposta por Deluiz, Ramos e Kuenzer. A pesquisa, de natureza qualitativa, foi realizada por meio de entrevistas com professores da instituição. Os resultados apontaram que a adoção do modelo de competências não se deu por opção pedagógica, mas por imposição legal das instâncias normativas. A identificação, definição e construção de competências que orientaram a organização curricular foram efetuadas através da perspectiva totalizante, ao buscar contemplar as diversas dimensões do conhecimento. A operacionalização desse modelo e o desenvolvimento da dimensão subjetiva das competências mostraram-se o maior desafio enfrentado pelos docentes ${ }^{3}$.

Palavras-chave educação profissional; modelo de competências; curso de nível técnico.
Abstract This article investigates the incorporation of the notion of 'skills' in the development of the Vocational Course on Laboratory in Biological Diagnosis in Health of the Joaquim Venâncio Polytechnic Health School (EPSJV), a technical and scientific unit of the Oswaldo Cruz Foundation (Fiocruz). The conducted research focused on determining validity and viability of understanding the skill-based curriculum in the light of the critical/emancipatory approach proposed by Deluiz, Ramos and Kuenzer. The qualitative research was comprised of interviews with teachers of the institution. Results show that the implementation of skillbased ideas was the result of legal determination, not an agreed pedagogical approach. Besides that, the identification, selection and development of skills guiding the development of the curriculum were performed with a totalizing perspective in mind, that is, encompassing all of the many existing dimensions of knowledge. Implementing this model and the subjective scope of skills were the most difficult challenges for teachers.

Keywords professional education; skill-based model; vocational course. 


\section{Introdução}

O problema enfocado pelo presente estudo é a adoção da lógica de competências na organização curricular do Curso Técnico de Laboratório em Biodiagnóstico em Saúde, da Escola Politécnica de Saúde Joaquim Venâncio (EPSJV), unidade técnico-científica da Fundação Oswaldo Cruz (Fiocruz). O interesse no assunto surgiu em virtude de a escola possuir particularidades quanto à formação de técnicos de nível médio e quanto à elaboração de currículo por competências.

A pesquisa foi operacionalizada a partir da análise da documentação do curso e da realização de entrevistas com a Coordenação de Ensino, com o diretor da Escola e com os seis professores do Núcleo de Educação Profissional de Laboratório (Nepel) que participaram da elaboração do referido currículo. Utilizamos como técnica de coleta de dados a entrevista semi-estrutura$\mathrm{da}$, que foi aplicada individualmente.

Depois de exaustiva leitura, foi necessário 'sentir' o material e efetuar a categorização, definida como o procedimento de destacar elementos dentro de determinado conteúdo utilizando os critérios de repetição e relevância (Turato, 2003). A partir desta metodologia, foi possível identificar as categorias que seriam tratadas através da análise de dados, tais como 'politecnia' e 'competências'. Também foram identificados nesta etapa os temas a serem abordados nas entrevistas: ressignificação do modelo de competências, metodologia e avaliação.

Inicialmente, abordaremos a viabilidade da ressignificação do modelo de competências na educação profissional e, a seguir, apresentaremos dados sobre o curso, o perfil dos entrevistados, assim como os principais aspectos revelados na pesquisa de campo.

\section{O modelo de competências e suas possibilidades na educação profissional}

A adoção do modelo de competências é um aspecto central na Reforma da Educação, pois ele está incorporado nos diferentes níveis de ensino. Entretanto, é na educação profissional que assume maior ênfase, como pode ser verificado nos Referenciais Curriculares da Educação Profissional. Cabe ressaltar a falta de consenso acerca do conceito de competência entre os educadores em geral (Novick e Gonzalez, 2003). Ao abordarmos a elaboração do currículo por competências, estamos trazendo à baila a questão da execução de uma diretriz pedagógica polêmica cujas origens nos remetem ao mundo do trabalho.

Deste modo, alguns autores acreditam que não basta ignorar ou apenas criticar a lógica das competências; é preciso encontrar um caminho possível 
para um modelo que já está posto na educação brasileira. Nessa linha, Kuenzer (2003), Ramos (2003a) e Deluiz (2001a e 2001b) propõem a ressignificação desse modelo, desenvolvendo a idéia de uma competência profissional ampliada que atenda, também, aos anseios dos trabalhadores. Essas autoras fundamentam-se em pressupostos marxistas, tais como os conceitos de politecnia e omnilateralidade, que se constituirão nos pilares para uma proposta de ressignificação do modelo de competências.

A educação politécnica, concebida por Marx e Engels, valoriza os princípios gerais e de caráter científico de todo processo de produção. A pedagogia marxista foi discutida por esses autores no documento intitulado "Instruções aos delegados", de 1866, no qual defendem a articulação entre trabalho e educação para crianças e adolescentes a partir dos nove anos de idade. Marx e Engels compreendiam a politecnia como sendo a integração do ensino intelectual à educação corporal e à educação tecnológica, esta entendida como o fundamento científico de todos os processos de produção, além da capacitação para o manejo dos instrumentos básicos dos diferentes ofícios.

A educação dos indivíduos deveria desenvolver a formação no sentido de aumentar todas as dimensões do humano, "que trabalha não apenas com as mãos, mas também com o cérebro e que, consciente do processo que desenvolve, domina-o e não é por ele dominado" (Marx e Engels apud Machado, 1991, p. 95).

O conceito de omnilateralidade, por sua vez, requer um desenvolvimento total, completo, multilateral não só da vida produtiva, mas também das necessidades e da capacidade de satisfação. A omnilateralidade, considerada como objetivo final da educação, deve ser alcançada através do desenvolvimento da capacidade produtiva alicerçada a uma

“(...) totalidade de capacidades de consumo e prazeres, em que se deve considerar, sobretudo, o gozo daqueles bens espirituais, além dos materiais, e dos quais o trabalhador tem estado excluído em conseqüência da divisão do trabalho" (Manacorda, 2000, p. 81).

Gramsci retoma as idéias de Marx no que se refere a omnilateralidade, concepção que diz respeito à realização/emancipação do homem através do trabalho. Diferente de Marx, Gramsci não se refere à inserção das crianças no processo produtivo. O trabalho para ele estaria inserido na escola a partir de dois elementos educativos fundamentais: noções de ciências naturais e noções de direitos e deveres do cidadão. Gramsci pretende desenvolver nas crianças a capacidade de trabalhar. Enquanto Marx valoriza o trabalho industrial, inclusive o seu aspecto prático, Gramsci privilegia o trabalho industrial como princípio educativo, assegurando certa autonomia em relação 
à fábrica. O pensador italiano considera como pressuposto pedagógico da escola unitária a construção ativa do conhecimento, partindo da premissa de que os homens são criativos (Gonzalez, 1996).

Em síntese, a perspectiva marxista de união entre ensino e trabalho no processo educativo busca formar não só bons profissionais, mas sujeitos ativos de seu tempo, transformadores de sua época e inseridos na vida social com capacidade de criação intelectual e prática.

Assim, a formação básica para o trabalho seria o princípio educativo na dimensão da tecnologia e da produção, com um plano político-pedagógico abrangente, integrando educação geral, formação profissional e formação política. Dessa forma, as mudanças advindas da natureza do trabalho, ocorridas principalmente pelo desenvolvimento de bases tecnológicas, científicas e instrumentais, interferem diretamente na organização social e na própria forma de viver da humanidade. É através da politecnia que se tenta aproximar o trabalho manual do intelectual, através da articulação entre ensino básico e ensino técnico.

Segundo Kuenzer (2003), existe um descompasso entre a práxis pedagógica e as mudanças ocorridas no processo produtivo na atualidade. Segundo esta autora, ainda não se tem uma proposta pedagógica que dê conta dessas novas necessidades; ela aponta como um caminho possível a ressignificação do modelo de competências através do praxismo ${ }^{4}$. A autora explica a articulação entre teoria e prática mediante a vinculação do conhecimento técnico-científico com outras dimensões do mundo social e com as competências tácitas necessárias ao atual estágio do processo produtivo. Esse conjunto de conhecimentos e competências deve possibilitar uma reflexão crítica por parte do indivíduo sobre sua inserção na vida social. O entendimento da competência como práxis requer a construção de um projeto político-pedagógico

“(...) resultante do contínuo movimento entre teoria e prática, entre pensamento e ação, entre velho e novo, entre sujeito e objeto, entre razão e emoção, entre homem e humanidade, que produz conhecimento e por isto revoluciona o que está dado, transformando a realidade" (Kuenzer, 2003, p. 90).

Observamos aqui uma semelhança com a formulação da matriz críticoemancipatória de competências apresentada por Deluiz (2001b, p. 22). Essa matriz está em construção e, além da ressignificação da noção de competência, busca valorizar a dimensão política de uma proposta de educação profissional ampliada. 


\section{Curso, perfil dos sujeitos e entrevistas: o desenrolar da pesquisa}

A EPSJV, criada no final da década de 1980, teve como perspectiva construir uma escola unitária e politécnica, resgatando o princípio da formação integral do ser humano. A utopia desse projeto foi dando espaço à construção de uma escola que atendesse aos princípios da politecnia e da omnilateralidade. Sendo assim, os cursos técnicos oferecidos pela instituição procuram integrar, dentro dessa lógica, o ensino médio à educação profissional.

O Curso Técnico de Laboratório em Biodiagnóstico em Saúde originou-se da fusão de dois cursos - Patologia Clínica e Histologia -, incorporando, ainda, novos conhecimentos e novas tecnologias. O curso da EPSJV foi escolhido por ser o único no Rio de Janeiro com o formato de Técnico de Laboratório em Biodiagnóstico em Saúde, englobando aquelas duas habilitações. Esse curso visa a formar profissionais para os diversos setores do trabalho em saúde, com competências nos campos da pesquisa biológica, produção tecnológica, promoção e atenção à saúde, questões éticas ligadas à saúde, entendimento da saúde como campo multidisciplinar, entre outras ${ }^{5}$.

Conforme mencionamos anteriormente, os sujeitos da pesquisa são os seis professores responsáveis pela elaboração do currículo do referido curso, a coordenadora de ensino e o diretor da escola. Com o objetivo de resguardar o anonimato dos entrevistados procurou-se criar uma codificação, utilizando um registro numérico, a fim de preservar a liberdade de opinião e a ética do trabalho (Lüdke e André, 1986). Dos seis professores do Nepel, cinco são servidores da Fiocruz, mas todos possuem uma carga horária semanal de 40 horas, desenvolvendo atividades de ensino e pesquisa. O tempo médio de docência dos entrevistados é de 15 anos e a formação acadêmica diversa caracteriza a multifuncionalidade da equipe (Quadro 1).

\section{Quadro1}

\begin{tabular}{lllc}
\hline \multicolumn{2}{l}{ Características profissionais dos professores entrevistados, Rio de Janeiro (2004) } & \\
\hline Código & $\begin{array}{l}\text { Forma de inserção } \\
\text { na instituição }\end{array}$ & Formação acadêmica & $\begin{array}{c}\text { Tempo de experiência } \\
\text { como docente }\end{array}$ \\
\hline 01 & Bolsista de pesquisa & Engenheiro químico & 7 \\
02 & Servidor & Mestre em Biologia Animal & 25 \\
03 & Servidor & Doutor em Ciências Biológicas & 27 \\
04 & Servidor & Mestre em Ciência Ambiental & 6 \\
05 & Servidor & Biólogo & 8 \\
06 & Servidor & Biólogo & 13 \\
07 & Servidor & Doutor em Educação & 15 \\
08 & Servidor & Especialista em Educação & 20 \\
\hline
\end{tabular}


Apresentaremos, a seguir, os principais aspectos das entrevistas realizadas com os professores do curso, em 2004. O modelo de competências funcionou como cerne da entrevista, mediante a formulação de questões sobre a elaboração do currículo. Segundo Ramos (2001a), a dimensão subjetiva da atividade profissional compreende a tomada de decisões, a iniciativa, a responsabilidade e a capacidade de trabalhar em equipe. A dimensão objetiva refere-se aos conteúdos trabalhados e às relações que a estruturam e que são mobilizadas pelos profissionais no desempenho de seu trabalho. As duas dimensões, quando articuladas e desenvolvidas de forma integrada, promovem o que a autora denomina "perspectiva totalizante" (Diagrama 1), citada pelos professores 01 e 02 durante a entrevista em oposição a uma concepção de educação profissional que valorize apenas a destreza técnica.

\section{Diagrama 1}

Dimensões do processo de trabalho

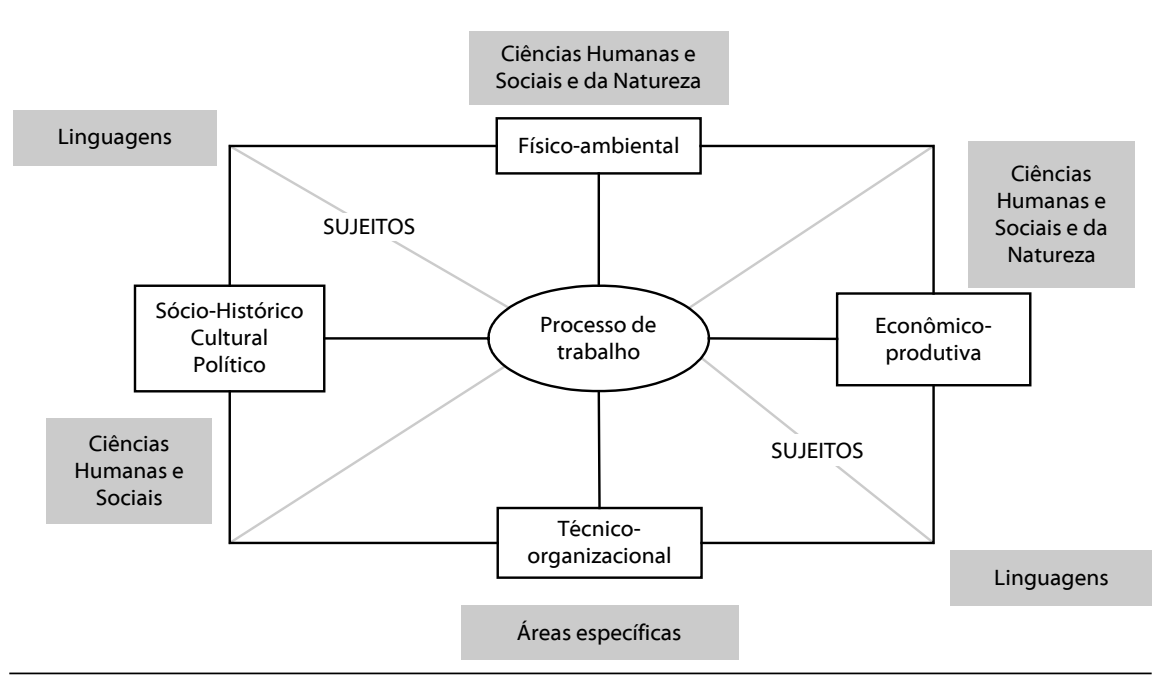

Fonte: RAMOS, Marise N. 2001a. Considerações sobre desenhos curriculares de nível técnico. Rio de Janeiro: EPSJV, Fiocruz. (Mimeo).

Todos os professores entrevistados, independentemente de sua posição em relação ao modelo de competência, mostraram-se favoráveis em relação à ressignificação desse modelo, defendendo a idéia de uma competência ampliada, que não enfatize somente as competências técnicas, mas também desenvolva um profissional-cidadão consciente de seu papel na sociedade. A politecnia foi considerada uma categoria de análise, uma vez que apareceu no discurso de todos os entrevistados, bem como sua relevância no plano 
político-pedagógico da EPSJV. A maioria dos entrevistados concluiu que formar profissionais dentro de uma concepção politécnica é garantir a eles o domínio dos fundamentos dos diferentes processos de trabalho, uma vez que o conhecimento e o aprofundamento dos diversos princípios que estão na base da organização da produção moderna propiciam um desenvolvimento multilateral do profissional, capaz de compreender, refletir e articular os princípios científicos sobre os quais ela se fundamenta.

A maioria dos professores entrevistados utilizou metodologias de ensino baseadas em contextos e situações reais, de modo que o conteúdo teórico foi ministrado em articulação com a prática, o que requer uma forte interrelação professor-aluno, já que o primeiro atua mais como orientador, não apenas como transmissor de conteúdos. A integração entre a teoria e a prática é um aspecto central nas reflexões de Kuenzer (2003) e Ramos (2003a), ao defenderem uma pedagogia contra-hegemônica das competências, mediante um referencial teórico-metodológico centrado na práxis humana. A realidade concreta produzida pelo homem é historicamente apropriada pela humanidade, no sentido de reproduzir de maneira contínua as funções humanas. A relação entre objetivação e apropriação desse processo, mediada pelo trabalho, é o que Ramos (2003a) chama de "práxis humana", e "nisto está o fundamento histórico do conhecimento, como motivação e resultado do agir humano de forma consciente e planejada (teleológica) e não somente adaptativa" (p. 110).

O conhecimento se constrói pela busca da realidade, em sua totalidade, e isso "pressupõe conceber o conhecimento como possibilidade ontológica e como produção social e histórica" (Ramos, 2003a, p. 110). Isto não significa dizer que devemos eliminar as disciplinas, uma vez que elas foram construídas historicamente para dar conta das especificidades das ciências. O que se defende é o diálogo interdisciplinar, sem comprometer a compreensão real dos conceitos científicos e suas inter-relações. A escolha da lógica das competências como pedagogia é uma das possibilidades e, quando feita, "deve considerar seus limites para a construção de conhecimentos a partir da escola" (Ramos, 2003b, p. 5).

Os professores concluíram que a avaliação deve ser permanente, através de instrumentos que façam com que os alunos reflitam e desenvolvam autonomia na busca de soluções e na determinação em atingir os objetivos da aprendizagem, além da capacidade de trabalhar em equipe.

Quanto aos maiores desafios encontrados na adoção do modelo de competências, concluiu-se que boa parte das competências exigidas atualmente é difícil de ser ensinada e precisa ser desenvolvida através de instrumentos que articulem o conhecimento de forma autônoma, reflexiva e crítica. Um dos professores entrevistados citou o Projeto Ciência e Cidadania, no qual 
o aluno, ao longo das três séries, desenvolve uma pesquisa científica com orientação de um ou mais professores, problematizando o trabalho em saúde com vistas a uma possível intervenção nesse processo. O formato modular do curso foi citado pelo entrevistado 03 como sendo a maior dificuldade na execução do modelo de competências, na medida em que existiria a necessidade, segundo ele, de um professor assistir a aula de todos os demais professores para fazer uma ligação, já que os conteúdos estão espalhados pelas diversas disciplinas e as competências devem ser desenvolvidas ao final de cada módulo.

$\mathrm{Na}$ fala de todos os entrevistados, ficou evidente o conhecimento dos princípios de flexibilidade, interdisciplinaridade e contextualização, eixos centrais do desenho curricular do modelo de competências segundo documentos oficiais do Ministério da Educação (MEC). Os professores foram unânimes em eleger a identidade epistemológica ${ }^{6}$ como o princípio utilizado para agrupamento dos componentes curriculares, o que contribuiu, segundo o professor 07, para caminhar no sentido da ressignificação do modelo de competências.

O Curso Técnico de Laboratório em Biodiagnóstico em Saúde da EPSJV apresenta particularidades, entre elas o fato de a escola pertencer à Fiocruz, instituição do Ministério da Saúde vinculada à carreira de Ciência e Tecnologia. Sendo assim, diferente de outras escolas técnicas federais, ela não possui vinculação direta com o MEC. Apesar disso, a EPSJV tem participado ativamente dos debates sobre formação integral dos trabalhadores junto à Secretaria de Educação Média e Tecnológica (Semtec).

A educação profissional constitui uma das dimensões do sistema educativo que mais se relaciona com outros setores da sociedade. As mudanças na economia, os novos paradigmas do processo produtivo, as inovações tecnológicas representam fontes de permanente instabilidade nos cursos de educação profissional. O interesse do empresariado em obter mão-de-obra barata, mas qualificada, estimula a criação de cursos técnicos rápidos, voltados para a prática.

Os cursos modulares podem ser uma armadilha nesse sentido, pois estimulam o aligeiramento dos cursos, com saídas intermediárias. Além disso, a não obrigatoriedade de se cursar todos os módulos faz com que os alunos, ávidos por entrar no mercado de trabalho, escolham apenas aqueles que possuem caráter mais técnico. Nesse sentido, o Curso Técnico de Laboratório em Biodiagnóstico em Saúde, por não possuir diferentes itinerários ou saídas intermediárias, não possibilita que o aluno o freqüente parcialmente.

Conforme mencionamos, o modelo de competências, adotado no Brasil a partir da Reforma da Educação, surge no mesmo quadro da reestruturação produtiva e das formas de organização do trabalho, carregado de forte ideologia em que os interesses da empresa são apresentados como interesses 
dos trabalhadores. A possibilidade de cada trabalhador vir a desenvolver as competências necessárias para sua vida profissional é considerada igual para todos, logo, os que não conseguem, são responsáveis por seu fracasso.

Esse lado sombrio do modelo de competências (Deluiz, 1996) é percebido por vários educadores como uma tentativa de encobrir as desigualdades sociais existentes no país. No curso em questão, dois aspectos colaboram para diminuir o fracasso e a conseqüente exclusão social. O primeiro é o número reduzido de alunos, uma vez que cada turma possui em média 13 estudantes. O segundo é a homogeneidade da turma, em que todos são adolescentes, cursam o ensino médio concomitante com a educação profissional da EPSJV, entraram através de uma acirrada disputa por concurso público e possuem como interesse a área de laboratório. A partir do primeiro semestre de 2005, esse quadro tende a se modificar, com a inclusão de alunos que optaram por fazer somente a educação profissional. A turma ficará mais heterogênea, com alunos jovens e adultos, cursando o ensino médio ou já formados.

A educação profissional da EPSJV foi concebida como um processo de construção social que garanta a formação do trabalhador dentro das bases científicas, ético-políticas, e consciente de seu papel como cidadão. Nesse contexto, a preocupação de todos os entrevistados com a proposta da educação profissional politécnica, na área da saúde, eixo central dessa escola, corrobora com a matriz crítico-emancipatória (Deluiz, 2001b), adotada como referencial teórico-conceitual, que busca a formação integral do trabalhador.

\section{Considerações finais}

Frente ao quadro complexo da educação profissional que ora se apresenta, a relevância desta pesquisa consiste no fato de que o conhecimento por ela produzido poderá vir a ser utilizado pela EPSJV em particular, na reconstrução permanente de seu projeto político-pedagógico, e pelas escolas de educação profissional em geral, com a possibilidade de fornecer novos elementos à complexa discussão sobre o modelo de competências, especialmente no que diz respeito à elaboração de currículo.

O desenvolvimento de pesquisas nas áreas de atuação do técnico em saúde merece também atenção especial, uma vez que cada vez mais os limites entre as profissões apresentam intercessões, mostrando que esses contornos tênues são altamente mutáveis e se deslocam de acordo com o mercado de trabalho e as novas tecnologias. Por isso, a preocupação deve centrar-se na pessoa, não no profissional.

Outro aspecto importante destacado por esse trabalho concentra-se na formação de docentes. No modelo de competências, o planejamento curricu- 
lar se fundamenta principalmente nos professores, que são responsáveis pela seleção dos conteúdos, pela criatividade e capacidade de elaborar situações e problemas que desenvolvam as competências necessárias para aquela disciplina. Um dos entrevistados defendeu a proposição de que o professor é mais importante que a escolha do referencial pedagógico, o que ilustra o peso desta classe na educação e, principalmente, no modelo de competências.

Finalmente, a revogação do decreto $\mathrm{n}^{\circ} 2.208 / 97$ e sua substituição pelo decreto $\mathrm{n}^{0} 5.154 / 04$, ao mesmo tempo em que restabeleceu a matrícula única para o ensino médio e a educação profissional, criou novas possibilidades de articulação para as escolas técnicas. Ficam previstas quatro formas de articulação entre o ensino profissional e o ensino médio: integrada na mesma instituição, integrada em diferentes instituições, concomitante e subseqüente 7 . O desafio está em desenvolver um currículo que promova uma verdadeira integração, por meio da qual o ensino regular e a educação profissional se complementem conformando uma totalidade. O Curso Técnico de Laboratório em Biodiagnóstico em Saúde teve sua primeira turma heterogênea, com alunos matriculados na educação profissional concomitante com o ensino médio e alunos cursando somente a educação profissional, seja de forma concomitante, seja de forma seqüencial, a partir do primeiro semestre de 2005. Essa experiência abrirá novas possibilidades de investigação na área de currículo integrado na educação profissional.

\section{Notas}

1 Professora da Escola Politécnica de Saúde Joaquim Venâncio, Fundação Oswaldo Cruz (EPSJV/Fiocruz). Mestre em Educação pela Universidade Estácio de Sá. <bia@fiocruz.br>

2 Professora adjunta da Universidade Estácio de Sá. Doutora em Educação pela Universidade Federal do Rio de Janeiro. <waniagonzalez@terra.com.br>

3 O presente estudo é parte de dissertação de mestrado em Educação, apresentada à Universidade Estácio de Sá (2005).

4 Praxismo: prática atrelada ao conhecimento teórico no sentido da transformação (Kuenzer, 2003).

${ }^{5}$ O processo de construção das competências dos módulos que compõem o curso é detalhado na dissertação “Currículo por competências: os desafios na implantação do Curso Técnico de Laboratório em Biodiagnóstico em Saúde da Escola Politécnica de Saúde Joaquim Venâncio (Fiocruz)". 
${ }^{6}$ Na elaboração do currículo do curso as disciplinas foram agrupadas em módulos, segundo organização a) de caráter epistemológico, agrupado por área de conhecimento (por exemplo, módulo Análises médicas de doenças infecto-parasitárias, disciplinas Bacteriologia, Virologia, Micologia, Protozoologia e Helmintologia); b) advinda dos contextos profissionais, com os componentes curriculares agrupados segundo os contextos em que podem ser exercidas as atividades (por exemplo, no caso de um laboratório de bacteriologia, atividades em indústria de alimentos, em laboratório de controle de qualidade, em produção de imunobiológicos) (Ramos, 2001a).

${ }^{7}$ Convém ressaltar que a resolução n ${ }^{\circ}$ 01/05 da Câmara de Educação Básica, Conselho Nacional de Educação, possibilita a redução da carga horária, na modalidade integrada, ao estabelecer no artigo 5 a exigência mínima de 3.200 horas. Antes da referida legislação, o aluno do ensino médio deveria cumprir 2.400 horas-aula, mais 1.200 de educação profissional, totalizando 3.600 horas-aula. Desta forma, a dualidade existe tanto no interior da educação profissional técnica de nível médio, como também entre os alunos deste nível que não cursam educação profissional.

\section{Referências}

BRASIL. 1996. Lei no. 9.394, de 20 de dezembro de 1996. Estabelece as Diretrizes e Bases da Educação Nacional. .1997. Decreto no. 2.208, de 17 de abril de 1997. Regulamenta o $\S 2^{\circ}$ do art. 36 e os arts. 30 a 42 da Lei no. 9.394, de 20 de dezembro de 1996, que estabelece as Diretrizes e Bases da Educação Nacional.

2004. Decreto no. 5.154, de 23 de julho de 2004. Regulamenta o $\S 2^{\circ}$ do art. 36 e os arts. 39 a 41 da lei no. 9.394, de 20 de dezembro de 1996, que estabelece as Diretrizes e Bases da Educação Nacional e dá outras providências.

MEC (Ministério da Educação). 1999. Parecer no. 16, de 05 de outubro de 1999. Diretrizes Curriculares para a Educação Profissional de Nível Técnico. Brasília: Câmara de Educação Básica.

.2000. Referenciais Curriculares Nacionais da Educação Profissional de Nível Técnico. Área profissional: saúde. Brasília: Secretaria de Educação Média e Tecnológica.

DELUIZ, Neise. 1996. A globalização econômica e os desafios à formação profissional. Boletim Técnico do Senac, v. 22, n. 2, p. 14-21. .2001a. Qualificação, competências e certificação: visão do mundo do trabalho. Formação, v. 1, n. 2, p. 5-15. .2001b. O modelo das competências profissionais no mundo do trabalho e na educação: implicações para o currículo. Boletim Técnico do Senac, v. 27, n. 3, p. 12-25.

GONZALEZ, Wânia R. C. 1996. Gramsci e a organização da escola unitária. Boletim Técnico do Senac, v. 22, n. 1, p. 26-33.

KUENZER, Acácia Z. 1986. Pedagogia da fábrica: as relações de produção e a educação do trabalhador. São Paulo: Cortez.

1999. Educação profissional: categorias para uma nova pedagogia do trabalho. Boletim Técnico do Senac, v. 25, n. 2, p. 19-29.

.2003. Competência como práxis: os dilemas da relação entre teoria e prática na educação dos trabalhadores. Boletim Técnico do Senac, v. 29, n. 1, p. 16-27.

LÜDKE, Menga; ANDRÉ, Marli E. D. A. 1986. Pesquisa em educação: abordagens qualitativas. São Paulo: EPU.

MACHADO, Lucília. 1991. Politecnia, escola unitária e trabalho. São Paulo: Cortez. 
MANACORDA, Mario A. 2000. Marx e a pedagogia moderna. São Paulo: Cortez. NOVICK, Victor; GONZALEZ, Wânia R. C. 2003. Competências e meio ambiente: uma análise crítica dos referenciais curriculares da educação profissional de nível técnico. Ambiente e Educação, v. 8, p. 95-116.

RAMOS, Marise N. 2001a. Considerações sobre desenhos curriculares de nivel técnico. Rio de Janeiro: EPSJV, Fiocruz. (Mimeo).

$.2001 \mathrm{~b}$. A pedagogia das competências: autonomia ou adaptação. Rio de Janeiro: Cortez.

.2002. Indicações metodológicas para a elaboração de currículos por com- petência para a educação profissional de nivel técnico em saúde. Rio de Janeiro: EPSJV, Fiocruz. (Mimeo).

.2003a. É possível uma pedagogia das competências contra-hegemônica? Relações entre pedagogia das competências, construtivismo e neopragmatismo. Trabalho, Educação e Saúde, v. 1, n. 1, p. 93-114.

.2003b. Conhecimento e competência: (não) está na hora de mudar seus conceitos. Revista do Ensino Médio, v.1, n. 2, p. 5.

TURATO, Egberto R. 2003. Tratado da metodologia da pesquisa clínico-qualitativa. Petrópolis: Vozes.

Recebido em 17/08/2005

Aprovado em 11/01/2006 